\title{
Climate Engineering in an Interconnected World: The Role of Tariffs
}

\author{
Markus Eigruber $^{1}$ (D) Franz Wirl $^{1}$
}

Published online: 25 April 2018

(C) The Author(s) 2018

\begin{abstract}
This paper investigates strategic trade policies as a response to negative externalities linked to climate engineering. Parties negatively affected, or which only perceive damages, may react to geoengineering by deploying trade sanctions, i.e. the imposition of tariffs. By introducing a dynamic trade model, we show that geoengineering-averse countries have an incentive to implement or increase existing tariffs when the other country uses geoengineering. Our contribution is to highlight that potential consequences on trade should be taken into account before climate engineering techniques are applied. This is particularly crucial in our globalized world since a successful climate policy demands large scale if not global cooperation.
\end{abstract}

Keywords Global warming · Externalities · Tariffs · Asymmetric differential game · Climate engineering

\section{Introduction}

The extraction and use of fossil fuels arising from the industrial revolution have brought tremendous and so far unseen growth in populations and incomes. ${ }^{1}$ However, these gains and the modern way of life have been bought by future damages due to anthropogenic change

1 Both, anyway linked by Malthusian dynamics, show negligible growth till around 1700 since the agricultural revolution $10,000 \mathrm{BC}$ [7].

Electronic supplementary material The online version of this article (https://doi.org/10.1007/s13235018-0261-y) contains supplementary material, which is available to authorized users.

$凶$ Markus Eigruber

markus.eigruber@univie.ac.at

Franz Wirl

franz.wirl@univie.ac.at

1 Faculty of Business, Economics and Statistics, University of Vienna, Oskar-Morgenstern-Platz 1, 1090 Vienna, Austria 
in the composition of Earth's atmosphere and the consequent increases in temperature. The concentration of atmospheric $\mathrm{CO}_{2}$ has increased from roughly $280 \mathrm{ppm}$ at pre-industrial times to well over $400 \mathrm{ppm}$ at present. Attempts to limit future damages have been notoriously slow due to a number of different reasons. Well recognized and analysed is the global tragedy of the commons involving more than seven billion people or roughly 200 governments. Moreover, the issue is inherently dynamic as global warming is caused by the stock of greenhouse gases accumulated since the industrial revolution (see [9] for their seminal contribution). If this were the only problem, it could be solved, as has been proven by the Montreal protocol concerning the global agreement of banning CFCs. Therefore, the major obstacles must be somewhere else. The primary issue is the lack of available substitutes, i.e. of renewable energy, at the necessary scale, cost and time. Further problems arise from the issue of proper time discounting (compare the debate in Nordhaus [18]), economic and meteorological uncertainties as well as geographic asymmetry. (Some latitudes will gain from global warming.) If these problems were not enough, one must add that governments cannot commit which renders R\&D into alternatives problematic and at least will slow them down [29]. Not to mention the naive policies of the past and present that ignore elementary system properties, e.g. in any electricity supply where the marginal unit is fossil, and this holds all over the world (even for Norway if one includes all Nord Pool countries), any addition of an electric car is fossil fuelled at $100 \%$. Nevertheless, electric cars are currently heavily subsidized not only directly at the purchase (e.g. buying an electric car in Austria warrants up to $€ 6000$ in subsidies for reducing GHG emissions if at all at a negligible amount) but also indirectly by being exempted from contributing to the infrastructure (roads, garages, police, hospitals, etc.), which is covered by petrol taxes. These resources would be better utilized somewhere else, e.g. in R\&D. Furthermore, constraints from asymmetric information (e.g. joint implementation, clean development mechanism, energy conservation, currently in the form of white certificates imposed on energy utilities, which make the 'butcher selling fish' and induce cheating, Ruff [21]) are entirely ignored, even the rebound effect is ignored (e.g. Bertoldi [5]) that already Jevons observed when analysing British coal in the nineteenth century.

The COP21 meeting in Paris generated some optimism in the form of a new agreement, but the lack of sanction mechanisms and insufficient early contributions together with recent experimental evidence of strategic behaviour in pledge and review processes curbs enthusiasm [3]. The problems listed above will not go away by wishful thinking. Indeed, recent trends towards more nationalism and protectionism may make it even more difficult to establish the necessary level of global cooperation to address climate change. Not to mention political changes like the election of Trump who promised to bring back coal.

Given the dire situation of reducing greenhouse gas emissions, alternative, technical solutions including climate — or geoengineering enter the debate. Defined as the “...deliberate large-scale intervention in the Earth's climate system, in order to moderate global warming" [24, p. ix] these methods can be broadly categorized into two classes: carbon dioxide removal (CDR) and solar radiation management (SRM). CDR methods directly remove $\mathrm{CO}_{2}$ from the atmosphere and are generally considered to be more safe but also more expensive and act on relatively long timescales. No large-scale CDR technology exists today that could remove $\mathrm{CO}_{2}$ from the atmosphere at the required rate and cost. With respect to SRM, the most promising technique is the injection of sulphate aerosols into the stratosphere, which aims at increasing Earth's albedo- the proportion of reflected sunlight. These aerosols increase reflectivity and therefore directly influence Earth's radiation balance. This method could effectively and timely lower global average temperatures at manageable projected costs. However, many considerable drawbacks associated with SRM should not be neglected [20]. 
It is unclear whether the modern climate engineering techniques would be captured by any of the already existing international treaties [27]. Many governance issues related to geoengineering exist. Who should decide and how should the optimal level of climate engineering be decided [2,28]? Climate modellers expect highly asymmetric effects due to changing precipitation patterns and, in general, warn of many unintended consequences not foreseen at present [1,23]. Another crucial argument against SRM is that once deployed, it is hard to stop even if evidence of substantial harm shows up, because terminating would lead to a sudden jump in temperatures.

The suggested technologies are at best imperfect substitutes for abatement. Therefore, more research is needed on technical as well as economic aspects of geoengineering, not only because of the continuing lack of sufficient abatement but also because of the increasing threat that many of Earth's systems may pass a tipping point relatively soon [13]. Some of the effects associated with catastrophic regime shifts can potentially be damped or at least delayed by appropriate technological intervention.

We develop a dynamic model of strategic interaction between two countries diverging in their perception of geoengineering and production possibilities. The model structure is similar to the asymmetric transboundary pollution game with a geoengineering option in Manoussi and Xepapadeas [14]. The difference is that we study a fully asymmetric trade game, in the sense of entirely different objectives for each country instead of different parameter values only. In particular, we let only one player apply geoengineering, as opposed to Manoussi and Xepapadeas [14] or Heyen et al. [12], where the prospects of a geoengineering war are studied. Given the interconnected channels of production via trade in a globalized world, production and hence abatement of others can be strategically influenced, especially in a noncooperative setting. Our aim is to account for trade by investigating the potential role of tariffs as an instrument of a country negatively affected by climate intervention of others. Economic modelling of negative external effects due to geoengineering is not new in the literature. Among others see [14-16,26]. How can one counter such climate intervention of others? Since the corresponding SRM techniques discussed above do not require global reach-once aerosols have been injected locally, stratospheric winds will distribute them globally-directly interfering with geoengineering practices seems unlikely. Due to the projected costs and uncertainty whether SRM is covered by existing treaties, it can be implemented without universal agreement, rendering veto power and voting mechanisms ineffective. While the potential for military conflict over the thermometer exists [22], we focus on an economic instrument often used in the past and present, namely tariffs. It is well known that from a general welfare perspective tariffs are inefficient as they distort prices. Nevertheless, they are often used to protect domestic industries or to sanction others. In the environmental area tariffs have traditionally played a minor role. Recently, tariff issues have been extensively discussed in two directions (but independent of geoengineering). First, the introduction of carbon border tax adjustments, i.e. carbon is also taxed if it enters as an input of imported goods. Second, the use of trade sanctions (e.g. exclusion of the WTO) has been proposed in the area of international environmental agreements in order to foster the necessary international cooperation in climate change mitigation policies [19].

The paper is structured as follows. Section 2 introduces the framework of the bilateral trade game. In Sect. 3 we investigate a setup where one country has monopoly power in a foreign market. We consider both cases where the trade partner, which is averse to geoengineering, accounts for temperature change and where it does not. Afterwards, in Sect. 4 we apply the same analysis to the case of duopolistic competition in production. Finally, Sect. 5 concludes. 


\section{Framework}

We consider a home country $(H)$, which exports its produced goods to a foreign country $(F)$ which might face negative spillovers from $H$ 's geoengineering activities. In the following, we explore two different foreign market structures-one where $F$ is not engaging in production (monopoly) and one where it does (Cournot). Global warming results from increasing the $\mathrm{CO}_{2}$ concentration in the atmosphere, which arises here solely due to total production in both countries,

$$
\dot{P}(t)=q_{\mathrm{H}}(t)+q_{\mathrm{F}}(t)-\delta P(t), \quad P(0)=P_{0},
$$

where $q_{\mathrm{H}}$ and $q_{\mathrm{F}}$ denote the quantities produced by industries in $H$ and $F$, respectively. Since depreciation is very small (Nordhaus [17] estimates a time constant of 200 years, but many natural scientists put this figure even much higher), we set $\delta=0$, which does not alter our main findings and simplifies some of the anyway cumbersome formulas.

We allow country $H$ the use of geoengineering, $g$, which has the capacity to reduce temperature levels (to $P-g$ ) at quadratic costs. Given that the speed of temperature decrease is effectively instantaneous, we let geoengineering reduce it immediately. ${ }^{2}$ The abovementioned negative external costs of SRM may arise from changing precipitation patterns or unwanted changes in average temperature, but may also be of perceived nature. Artificially changing major geophysical properties of Earth's systems is a controversial topic with little awareness and knowledge of the general public (see Corner et al. [8] for an overview). However, as attention devoted to this topic increases, public attitudes will form more clearly. The range of public's perception will be wide, from complete acceptance on one side to outright rejection on the other, and there will likely be more weight attached to the latter part of the spectrum [11,24]. Scepticism like 'humans should never interfere with Earth's fundamental systems' does not seem entirely unjustified, especially given past experiences with originally very promising technologies such as nuclear power. Indeed, currently we observe this in Europe in the context of genetically modified food. Therefore, we assume in our baseline models that country $F$ neglects the increasing pollution stock but perceives geoengineering negatively. We propose a linear negative externality term (instead of the standard quadratic one) in order to account for the fact that the marginal damage from geoengineering is already large at low levels. Afterwards, we relax the assumption of $F$ 's ignorance in the two respective models and explore the effects of both damages on optimal trade policies.

\section{Monopoly}

The exports of the firm in $H$ are the only source of income; hence, the firm's and the government's objective coincides. ${ }^{3}$ In addition, $H$ 's firm has market power in $F$. If $p(t)$ denotes the price charged per unit of the good in period $t$, foreign normalized and linear demand is given by $1-p(t)$. The final consumer price consists of $H$ 's export price $p$ and $F$ 's imposition of tariff $\tau$. Therefore, the profit of $H$ 's firm is

$$
\pi(p, \tau)=(1-p(t)-\tau(t)) p(t)
$$

\footnotetext{
2 Similar, but simpler compared to the way it is modelled in Manoussi and Xepapadeas [14].

3 In this sense we assume that the firm or the industry which is producing is either owned by $H$ or that there exists a competitive market in $H$ for which the government charges export taxes (which affect prices).
} 
if we ignore costs (or, respectively, normalize for constant unit costs). The stock of pollution evolves according to (1), which implies

$$
\dot{P}(t)=1-p(t)-\tau(t), \quad P(0)=P_{0} .
$$

The objective of country $H$ is to maximize the net present value (using the constant discount rate $r>0$ ) of profits minus expenditures for geoengineering and convex damage due to increased temperature,

$$
\max _{\substack{p(t) \geq 0 \\ g(t) \geq 0}} \int_{0}^{\infty} e^{-r t}\left[\left(p(t)-p(t)^{2}-\tau(t) p(t)\right)-\frac{g(t)^{2}}{2}-\frac{\alpha_{\mathrm{H}}}{2}(P(t)-g(t))^{2}\right] \mathrm{d} t .
$$

The benevolent government of country $F$ maximizes its net present value of welfare consisting of consumer surplus from imports and tariff revenues less damages caused by geoengineering and changes in temperature,

$$
\max _{\tau(t)} \int_{0}^{\infty} e^{-r t}\left[\frac{1}{2}\left(1-2 p(t)+p(t)^{2}-\tau(t)^{2}\right)-\beta g(t)-\frac{\alpha_{\mathrm{F}}}{2}(P(t)-g(t))^{2}\right] \mathrm{d} t .
$$

\subsection{F Disregards Temperature Changes}

First, we analyse the case that country $F$ does not care about global warming, i.e. for $\alpha_{\mathrm{F}}=0$. We are interested in a subgame-perfect and hence a strongly time-consistent equilibrium [10] and thus compute the (linear) Markov-perfect strategies for each player. Therefore, we set up the Hamilton-Jacobi-Bellman equations (now and subsequently suppressing the argument of time),

$$
\begin{aligned}
& r V_{\mathrm{H}}=\max _{p \geq 0, g \geq 0}\left\{\left(p-p^{2}-\tau p\right)-\frac{g^{2}}{2}-\frac{\alpha_{\mathrm{H}}}{2}(P-g)^{2}+V_{\mathrm{H}}^{\prime}(1-p-\tau)\right\}, \\
& r V_{\mathrm{F}}=\max _{\tau}\left\{\frac{1}{2}\left(1-2 p+p^{2}-\tau^{2}\right)-\beta g+V_{\mathrm{F}}^{\prime}(1-p-\tau)\right\},
\end{aligned}
$$

where $V_{i}$ represents the value function of country $i=H, F$. The intraperiod Nash equilibrium results from solving the first-order optimality conditions on the right hand sides of (5) for both players,

$$
\begin{aligned}
p & =\frac{1-\tau-V_{\mathrm{H}}^{\prime}}{2}, \\
g & =\frac{\alpha_{\mathrm{H}}}{1+\alpha_{\mathrm{H}}} P, \\
\tau & =-V_{\mathrm{F}}^{\prime} .
\end{aligned}
$$

The exporting country $H$ chooses a price above the monopoly level given the tax. The reasons are that $H$ is aware of future damages associated with today's emissions $\left(V_{\mathrm{H}}^{\prime}<0\right)$ and therefore has an incentive to preempt $F$ 's future taxes. The choice of geoengineering is given right away by a feedback rule independent of the value function. Country $F$ 's tax looks Pigouvian, because it is not explicitly correcting for the monopoly distortion as the tax equals the net present value of the marginal damage from higher temperatures. Nevertheless, it appropriates parts of $H$ 's monopoly rent.

Linear quadratic games allow for quadratic solutions of the value functions, which imply linear strategies. The analysis of equilibria in nonlinear strategies $[9,25]$ is ignored due to 
the complexity of our asymmetric framework. Therefore, we guess

$$
\begin{aligned}
V_{\mathrm{H}}:=\theta_{1}+\theta_{2} P+\frac{\theta_{3}}{2} P^{2} & \Longrightarrow V_{\mathrm{H}}^{\prime}=\theta_{2}+\theta_{3} P, \\
V_{\mathrm{F}}:=\psi_{1}+\psi_{2} P+\frac{\psi_{3}}{2} P^{2} & \Longrightarrow V_{\mathrm{F}}^{\prime}=\psi_{2}+\psi_{3} P .
\end{aligned}
$$

Plugging (6) and (7) into (5) and rearranging terms yield a system of six simultaneous equations in the six coefficients of the two value functions $V_{\mathrm{H}}$ and $V_{\mathrm{F}}$ in (7). Since optimal strategies do not depend on the intercepts, we can drop them and solve the resulting system of four equations in $\theta_{2}, \theta_{3}, \psi_{2}$ and $\psi_{3}$.

Proposition 1 The linear Markov-perfect strategies for the asymmetric differential game are given by (6) and (7) with the coefficients

$$
\begin{aligned}
& \theta_{2}=2 A\left[(2 B-C-D)\left(r+r \alpha_{\mathrm{H}}-\alpha_{\mathrm{H}} \beta\right)\right], \\
& \theta_{3}=\alpha_{\mathrm{H}} A[2 D-C-4 B], \\
& \psi_{2}=\alpha_{\mathrm{H}} \beta A[D-2 B-2 C]-r A\left(1+\alpha_{\mathrm{H}}\right)[C+D-2 B], \\
& \psi_{3}=\alpha_{\mathrm{H}} A[C+D-2 B]
\end{aligned}
$$

and

$$
\begin{aligned}
A & =\frac{1}{9 \alpha_{\mathrm{H}} r^{2}\left(1+\alpha_{\mathrm{H}}\right)^{2}}, & B & =\sqrt{r^{4}\left(1+\alpha_{\mathrm{H}}\right)^{3}\left(3 \alpha_{\mathrm{H}}+r^{2}\left(1+\alpha_{\mathrm{H}}\right)\right),} \\
C & =3 r \alpha_{\mathrm{H}}\left(1+\alpha_{\mathrm{H}}\right), & D & =2 r^{3}\left(1+\alpha_{\mathrm{H}}\right)^{2} .
\end{aligned}
$$

It holds that $\psi_{2}<0$ for all $r, \beta, \alpha_{\mathrm{H}}>0$ and that $\theta_{2}<0$ for $r, \alpha_{\mathrm{H}}>0$ and

$$
\alpha_{\mathrm{H}}<\frac{r}{\beta-r} \Longleftrightarrow \beta<\frac{r\left(1+\alpha_{\mathrm{H}}\right)}{\alpha_{\mathrm{H}}},
$$

which is assumed to hold throughout the paper. In terms of the coefficients that determine the slopes, we find that $\psi_{3}>0$ and $\theta_{3}<0$ for all $r, \beta, \alpha_{\mathrm{H}}>0$, meaning that the optimal price strategy is always upwards-sloping while the optimal tariff is downwards-sloping. Sensitivity analysis yields

$$
\begin{aligned}
\partial \theta_{2} / \partial \beta & =2 \alpha_{H} A(D+C-2 B)>0, \\
\partial \psi_{2} / \partial \beta & =\alpha_{\mathrm{H}} A(D-2 B-2 C)<0, \\
\partial \theta_{3} / \partial \beta & =\partial \psi_{3} / \partial \beta=0,
\end{aligned}
$$

which implies that a larger externality due to geoengineering (i.e. a larger $\beta$ ) decreases the intercept of the optimal price strategy of the exporter and increases the intercept of the optimal tariff strategy but does not affect the slopes of the strategies due to linear external costs in $g$. As a consequence, lower prices and larger tariffs are charged for all pollution stock levels if the externality of geoengineering is larger.

Clearly, $\left.\lim _{\alpha_{\mathrm{H}} \rightarrow 0} \theta_{i}\right|_{\beta=0}=\left.\lim _{\alpha_{\mathrm{H}} \rightarrow 0} \psi_{i}\right|_{\beta=0}=0$ for $i=2,3$ imply the static monopoly price and an absence of tariffs. A tax would generate revenues at the expense of consumer surplus leading to a triangular dead-weight loss. However, due to $\left.\psi_{2}\right|_{\alpha_{\mathrm{H}}>0, \beta=0}<0$ and $\left.\psi_{3}\right|_{\alpha_{\mathrm{H}}>0, \beta=0}>0$ country $F$ finds it optimal to implement a tax transiently even if it does not suffer from $H$ 's geoengineering activity. The reason is that for larger values of $P$, country $H$ (suffering from increased temperatures) has an incentive to charge a higher price, which induces less production and hence lower pollution stocks over time. This deviation to larger price levels of $H$ is anticipated and can be exploited by $F$ through the introduction of a tariff. 
On these grounds $F$ accrues rents through its tax policy (part of the price increase that $H$ plans) which would otherwise go to $H$. Hence, despite its Pigouvian look the optimal tariff includes a rent shifting component. The Pigouvian component of the tax is given by

$$
\begin{aligned}
\tau_{\text {Pig }}=\tau-\left.\tau\right|_{\beta=0} & =-\psi_{2}-\psi_{3} P-\left(-\left.\psi_{2}\right|_{\beta=0}-\left.\psi_{3}\right|_{\beta=0} P\right) \\
& =-\psi_{2}+\left.\psi_{2}\right|_{\beta=0} \\
& =\alpha_{\mathrm{H}} \beta A(2 B+2 C-D),
\end{aligned}
$$

and is thus constant with respect to time and the pollution stock, which rests at

$$
P_{\infty}=r\left(1+\frac{1}{\alpha_{\mathrm{H}}}\right)-\beta .
$$

Figure 1 plots the time paths implied by the above Markov-perfect equilibrium. The six paths correspond to 0.2 increments in the external costs from geoengineering, $\beta$. A larger externality leads $F$ to charge higher tariffs since this is its only option of sanctioning $H$. Surprisingly, the tax is declining over time although external costs are increasing due to more geoengineering, countering the increase in $\mathrm{CO}_{2}$ concentration. The reason is that, as mentioned above, the tax includes a component that appropriates monopoly rents. The environmental Pigouvian component, $\tau_{\text {Pig }}$, is increasing in $\beta$ but constant over time (as computed above). Facing higher tariffs, country $H$ has an incentive to lower its export prices. Since in steady state there cannot be positive production, the consumer price must equal the choke price, $\tau_{\infty}+p_{\infty}=1$, which together with the previous arguments implies that the quantity imported declines faster for more geoengineering-averse countries. This in turn decreases the stock of pollution too, which reduces $H$ s incentive to use geoengineering in the first place. This is what country $F$ wants to achieve when introducing and increasing tariff levels.

Figure 2 compares total payoffs for each country under a tariff-free regime (solid lines) vs. the regime in which the tariff option is introduced (dashed lines) for $P_{0}=0$. The payoffs under the tariff-free regime are derived from the trivial problem defined by setting $\tau(t)=0$ for all $t$. Under this scenario the exporter does not face any reaction to geoengineering. Therefore, it can produce the optimal quantity and choose its subjectively optimal geoengineering level in each period yielding a payoff invariant to changes in $\beta$. If the importing country introduces a tariff, $H$ 's payoffs decline the higher the external costs experienced by $F$ are due to the fact that from its point of view tariffs sub-optimally distort prices upwards.

Of course, the payoffs of country $F$ are always higher in the tariff regime. A geoengineering-averse importer without the option of a tariff would face substantial losses, since the exporter would heavily produce and geoengineer and in turn offload this externality on $F$. Hence, the deployment of tariffs, increasing in $\beta$, forces the exporting country to internalize parts of this externality.

\subsection{F Accounts for Temperature Changes}

How will the results change if both countries faced damages from the pollution stock? We obtain closed-form solutions for Markov-perfect strategies but do not report them due to their length. ${ }^{4}$ Compared to (9) the limiting value of the stock is now also influenced by $\alpha_{\mathrm{F}}$ and given by

$$
P_{\infty}=\frac{\left(\alpha_{\mathrm{H}}+1\right)\left(\alpha_{\mathrm{H}}(r-\beta)+r\right)}{\alpha_{\mathrm{F}}+\alpha_{\mathrm{H}}\left(1+\alpha_{\mathrm{H}}\right)} .
$$

4 Please see the Online Appendix. 

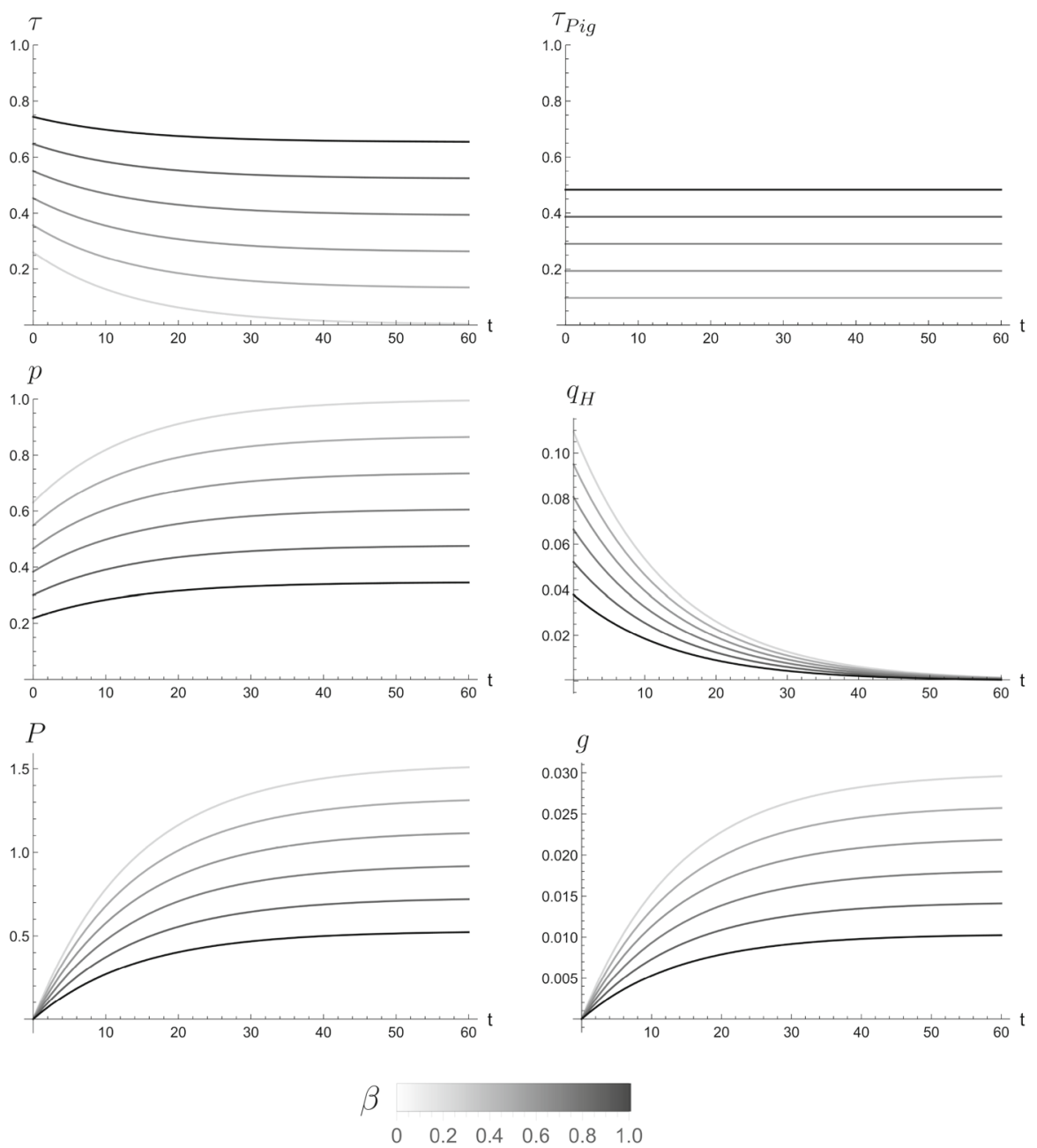

Fig. 1 Trajectories of controls and state over time with $\alpha_{\mathrm{H}}=0.02$ and $r=0.03$

Fig. 2 Total payoffs for both countries under a tariff-free (solid) and a tariff regime (dashed)

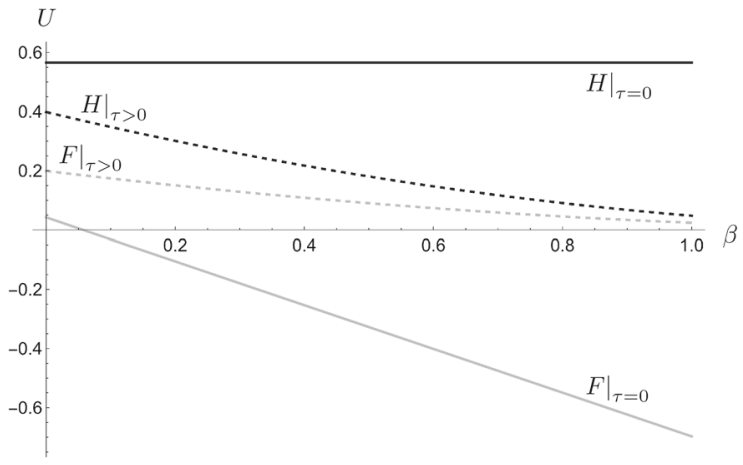




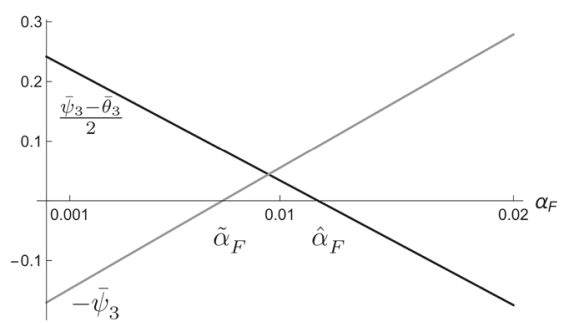

(a)

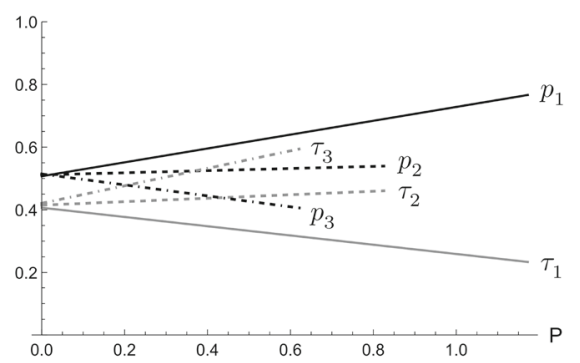

(b)

Fig. 3 a Slopes of optimal price and tax. b Price and tax strategies for three different scenarios up to the respective steady state

The qualitative result of the previous subsection still holds, i.e. $\partial \tau / \partial \beta>0, \forall P$ but now due to $\alpha_{\mathrm{F}} \neq 0$ there exists the possibility for a qualitative difference in the slopes of the strategies.

Proposition 2 The slopes of the optimal price and tariff strategies change sign at

$$
\begin{aligned}
& \hat{\alpha}_{\mathrm{F}}:=\frac{1}{8}\left(1+\alpha_{\mathrm{H}}\right)\left[\alpha_{\mathrm{H}}\left(4-r^{2}\right)-r^{2}+r \sqrt{\left(1+\alpha_{\mathrm{H}}\right)\left(r^{2}+8 \alpha_{\mathrm{H}}+\alpha_{\mathrm{H}} r^{2}\right)}\right], \\
& \tilde{\alpha}_{\mathrm{F}}:=\frac{1}{2}\left(1+\alpha_{\mathrm{H}}\right)\left[\alpha_{\mathrm{H}}\left(1+r^{2}\right)+r^{2}-r \sqrt{\left(1+\alpha_{\mathrm{H}}\right)\left(r^{2}+2 \alpha_{\mathrm{H}}+\alpha_{\mathrm{H}} r^{2}\right)}\right],
\end{aligned}
$$

respectively. Specifically,

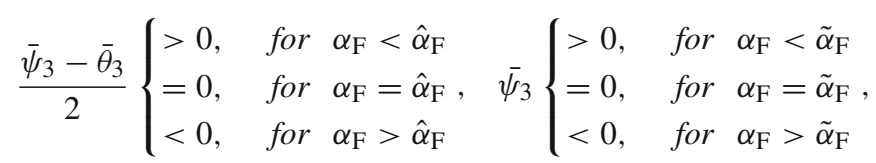

where we have $p=\frac{1+\bar{\psi}_{2}-\bar{\theta}_{2}}{2}+\frac{\bar{\psi}_{3}-\bar{\theta}_{3}}{2} P, \tau=-\bar{\psi}_{2}-\bar{\psi}_{3} P$ and the bar denotes coefficients of the extended model.

Due to $\hat{\alpha}_{\mathrm{F}} \neq \tilde{\alpha}_{\mathrm{F}}$ there exist three qualitatively different price/tariff strategies. Figure 3 a shows the slopes of the optimal price and tariff strategies with respect to $\alpha_{\mathrm{F}}$ for $r=0.03, \beta=0.3$ and $\alpha_{\mathrm{H}}=0.02$. Figure $3 \mathrm{~b}$ plots the strategies in state space for the same parameter values and where $\alpha_{\mathrm{F}}$ is varied in three steps from $0.001,0.01$, to 0.02 . At a low stock externality in $F$, the export price is increasing and the tax is decreasing as the $\mathrm{IO}$ element-acquiring parts of the monopoly rent-dominates. At high external costs, the Pigouvian element dominates the IO element, such that the tariff increases (with respect to state and time) and prices have to decrease. In the intermediate case, both tax and export price are increasing. Hence, $F$ chooses decreasing (increasing) tariffs over time if it suffers relatively little (much) of increased temperature. In the case where $F$ gains from global warming $\left(\alpha_{\mathrm{F}}<0\right)$ the tariff may become negative at later stages. This induces $H$ to produce more (e.g. by offering tax incentives) than it would find optimal otherwise. 


\section{Oligopoly}

We extend our framework for international competition. More precisely, two firms (or industries), one located in $H$ the other in $F$, compete a la Cournot in $F$ and $F$ 's government accounts for the profits of its domestic firm. Total inverse demand for the homogeneous good in $F$ is given by the normalized and linear relation $1-q_{\mathrm{H}}-q_{\mathrm{F}}$, in line with the single supplier case. We now allow $F$ 's government to impose a tax/subsidy scheme $\left(\tau_{\mathrm{H}}, \tau_{\mathrm{F}}\right)$ on both industries. Ignoring costs, the firms' profits are

$$
\begin{aligned}
\Pi_{\mathrm{H}} & =\left(1-q_{\mathrm{H}}-q_{\mathrm{F}}-\tau_{\mathrm{H}}\right) q_{\mathrm{H}}, \\
\Pi_{\mathrm{F}} & =\left(1-q_{\mathrm{H}}-q_{\mathrm{F}}-\tau_{\mathrm{F}}\right) q_{\mathrm{F}},
\end{aligned}
$$

which imply the Cournot-Nash outputs,

$$
\begin{aligned}
& q_{\mathrm{H}}=\frac{1-2 \tau_{\mathrm{H}}+\tau_{\mathrm{F}}}{3}, \\
& q_{\mathrm{F}}=\frac{1-2 \tau_{\mathrm{F}}+\tau_{\mathrm{H}}}{3} .
\end{aligned}
$$

We are interested in how the government of $F$ chooses $\tau_{\mathrm{H}}$ and $\tau_{\mathrm{F}}$ under climate intervention of $H$ with the assumption that the two firms choose the equilibrium Cournot quantities in (11) in each period. That is, while the governments act intertemporally, the firms in both countries act intratemporally only. Hence, country $H$ 's objective is given by

$$
\max _{g \geq 0} \int_{0}^{\infty} e^{-r t}\left[\left(1-q_{\mathrm{H}}-q_{\mathrm{F}}-\tau_{\mathrm{H}}\right) q_{\mathrm{H}}-\frac{g^{2}}{2}-\frac{\alpha_{\mathrm{H}}}{2}(P-g)^{2}\right] \mathrm{d} t,
$$

whereas $F$ maximizes consumer surplus, producer surplus and tax revenues minus damages caused by $H$ 's geoengineering and increased temperature (note that the taxes or subsidies, which $F$ imposes on its local firm, cancel),

$$
\begin{aligned}
& \max _{\tau_{\mathrm{H}}, \tau_{\mathrm{F}}} \int_{0}^{\infty} e^{-r t}\left[\frac{\left(q_{\mathrm{H}}+q_{\mathrm{F}}\right)^{2}}{2}+\left(1-q_{\mathrm{H}}-q_{\mathrm{F}}\right) q_{\mathrm{F}}+\tau_{\mathrm{H}} q_{\mathrm{H}}-\beta g\right. \\
& \left.\quad-\frac{\alpha_{\mathrm{F}}}{2}(P-g)^{2}\right] \mathrm{d} t,
\end{aligned}
$$

subject to

$$
\begin{aligned}
& \dot{P}=q_{\mathrm{H}}+q_{\mathrm{F}}=\frac{2-\tau_{\mathrm{H}}-\tau_{\mathrm{F}}}{3}, \quad P(0)=P_{0}, \\
& q_{\mathrm{H}}=\frac{1-2 \tau_{\mathrm{H}}+\tau_{\mathrm{F}}}{3}, q_{\mathrm{F}}=\frac{1-2 \tau_{\mathrm{F}}+\tau_{\mathrm{H}}}{3} .
\end{aligned}
$$




\subsection{F Disregards Temperature Changes}

We employ the same solution procedure as before. The HJB equations corresponding to this scenario are

$$
\begin{aligned}
r V_{\mathrm{H}}= & \max _{g \geq 0}\left\{\frac{1}{9}\left(\tau_{\mathrm{F}}-2 \tau_{\mathrm{H}}+1\right)^{2}-\frac{g^{2}}{2}-\frac{\alpha_{\mathrm{H}}}{2}(P-g)^{2}\right. \\
& \left.+V_{\mathrm{H}}^{\prime}\left(\frac{2-\tau_{\mathrm{H}}-\tau_{\mathrm{F}}}{3}\right)\right\}, \\
r V_{\mathrm{F}}= & \max _{\tau_{\mathrm{H}}, \tau_{\mathrm{F}}}\left\{\frac{1}{6}\left(2+2 \tau_{\mathrm{H}}-2 \tau_{\mathrm{F}}+2 \tau_{\mathrm{H}} \tau_{\mathrm{F}}-3 \tau_{\mathrm{H}}^{2}-\tau_{\mathrm{F}}^{2}\right)-\beta g\right. \\
& \left.+V_{\mathrm{F}}^{\prime}\left(\frac{2-\tau_{\mathrm{H}}-\tau_{\mathrm{F}}}{3}\right)\right\} .
\end{aligned}
$$

We guess

$$
\begin{aligned}
& V_{\mathrm{H}}:=\lambda_{1}+\lambda_{2} P+\frac{\lambda_{3}}{2} P^{2}, \\
& V_{\mathrm{F}}:=\mu_{1}+\mu_{2} P+\frac{\mu_{3}}{2} P^{2}
\end{aligned}
$$

and derive the following FOC's

$$
\begin{aligned}
g & =\frac{\alpha_{\mathrm{H}}}{1+\alpha_{\mathrm{H}}} P, \\
\tau_{\mathrm{H}} & =-V_{\mathrm{F}}^{\prime}=-\mu_{2}-\mu_{3} P, \\
\tau_{\mathrm{F}} & =-1-2 V_{\mathrm{F}}^{\prime}=-1-2 \mu_{2}-2 \mu_{3} P .
\end{aligned}
$$

As in the previous section we determine the strategy relevant coefficients $\left(\lambda_{2}, \lambda_{3}, \mu_{2}, \mu_{3}\right)$ by comparing coefficients in (15) using (16) and (17). Since $\mu_{3}=0$ the value function of $F$ is linear in the state, thus rendering the following constant tariffs.

Proposition 3 The linear Markov-perfect strategies are given by

$$
g=\frac{\alpha_{\mathrm{H}}}{1+\alpha_{\mathrm{H}}} P, \quad \tau_{\mathrm{H}}=\frac{\beta \alpha_{\mathrm{H}}}{r+r \alpha_{\mathrm{H}}}, \quad \tau_{\mathrm{F}}=-1+\frac{2 \beta \alpha_{\mathrm{H}}}{r+r \alpha_{\mathrm{H}}} .
$$

Both taxes levied on the industry in $H$ as well as $F$ (the latter one may be negative and thus a subsidy) are constant with respect to time and are increasing in $\beta$. These policies shut down the imports from $H$ and imply a subsidy/tax for the industry located in $F$,

$$
q_{\mathrm{H}}=0, \quad q_{\mathrm{F}}=1-\frac{\beta \alpha_{\mathrm{H}}}{r+r \alpha_{\mathrm{H}}} .
$$

Note that

$$
q_{\mathrm{F}}>0 \Longleftrightarrow \beta<\frac{r\left(1+\alpha_{\mathrm{H}}\right)}{\alpha_{\mathrm{H}}},
$$

which is assured due to assumption (8). Since $F$ does not suffer from increased temperatures, it continues to produce forever (only correcting for the negative externality of $H$ 's geoengineering), resulting in boundless accumulation of the stock of pollution, i.e. $P_{\infty}=\infty$. This obvious lack of a steady state sets this case apart from all the others in which $P$ converges. 
We also observe that $F$ changes its domestic tariff policy from a subsidy to a tax. In fact, $F$ subsidizes its own firm for

$$
\beta \in\left[0, r\left(1+\alpha_{\mathrm{H}}\right) /\left(2 \alpha_{\mathrm{H}}\right)\right)
$$

and taxes it for $\beta \in\left(r\left(1+\alpha_{\mathrm{H}}\right) /\left(2 \alpha_{\mathrm{H}}\right), r\left(1+\alpha_{\mathrm{H}}\right) /\left(\alpha_{\mathrm{H}}\right)\right)$, where the upper bound is again due to (8). This argument that non-competitive polluting firms may voluntarily internalize and even over-internalize the external costs dates back to Buchanan [6].

The economic rational behind this specific tariff policy can be explained as follows. Suppose for the moment that $\beta=0$. In this case the government in $F$ chooses to subsidize its industry in order to incentivize it to produce at the welfare optimal level $\left(q_{\mathrm{F}}=1\right)$ since the subsidies - as pure transfers-play no role. No tariff for the industry in $H$ is necessary. Now, as $\beta$ increases $F$ 's government has an incentive to reduce total production in order to lower geoengineering efforts by $H$. To do this it needs to cut emissions of its own industry too. However, as it lowers production, entry of the firm located in $H$ becomes profitable. This is not in the interest of $F$ 's government since one unit provided by $F$ 's firm is worth more than one unit provided by $H$ 's firm. Hence, it imposes taxes on exports of $H$ in order to deter entry.

\subsection{F Accounts for Temperature Changes}

Finally, we study the case of $\alpha_{\mathrm{F}}>0$. The FOC's are still given by (17) with a different set of coefficients.

Proposition 4 The linear Markov-perfect strategies for the game of international competition and concern about global warming are given by

$$
\begin{aligned}
& g=\frac{\alpha_{\mathrm{H}}}{1+\alpha_{\mathrm{H}}} P, \\
& \tau_{\mathrm{H}}=1+M+\left(N-\frac{1}{2} r\right) P, \\
& \tau_{\mathrm{F}}=1+2 M+(2 N-r) P,
\end{aligned}
$$

with

$$
\begin{aligned}
& M=\frac{\left(r+\alpha_{\mathrm{H}} r-\alpha_{\mathrm{H}} \beta\right)\left(r+\alpha_{\mathrm{H}} r-\sqrt{4 \alpha_{\mathrm{F}}+r^{2}\left(1+\alpha_{\mathrm{H}}\right)^{2}}\right)}{2 \alpha_{\mathrm{F}}}, \\
& N=\frac{\sqrt{4 \alpha_{\mathrm{F}}+r^{2}\left(1+\alpha_{\mathrm{H}}\right)^{2}}}{2\left(1+\alpha_{\mathrm{H}}\right)} .
\end{aligned}
$$

Since

$$
\begin{aligned}
\frac{\partial \tau_{\mathrm{H}}}{\partial \beta} & =\frac{\alpha_{\mathrm{H}}\left(-r\left(1+\alpha_{\mathrm{H}}\right)+\sqrt{4 \alpha_{\mathrm{F}}+r^{2}\left(1+\alpha_{\mathrm{H}}\right)^{2}}\right)}{2 \alpha_{\mathrm{F}}}>0, \\
\frac{\partial \tau_{\mathrm{F}}}{\partial \beta} & =2 \frac{\partial \tau_{\mathrm{H}}}{\partial \beta},
\end{aligned}
$$

for $\alpha_{\mathrm{H}}, \alpha_{\mathrm{F}}, r>0$, we find that both tariffs are increasing in $\beta$. This is due to the fact that $F$ now also suffers from pollution and hence has to reduce its own production over time. It does so by increasingly taxing its own industry-no subsidy is given in the later and warmer stages. Note that for $\lim _{\alpha_{\mathrm{F}} \rightarrow 0}$ the results of the previous model apply, i.e. initial subsidies 


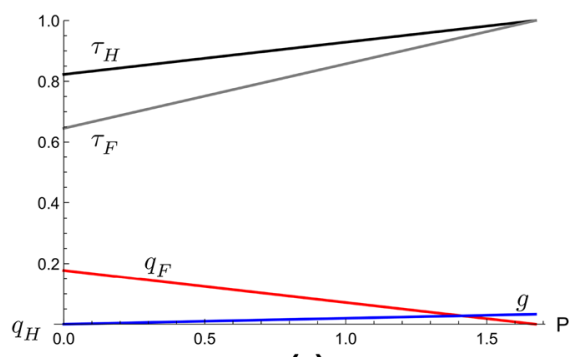

(a)

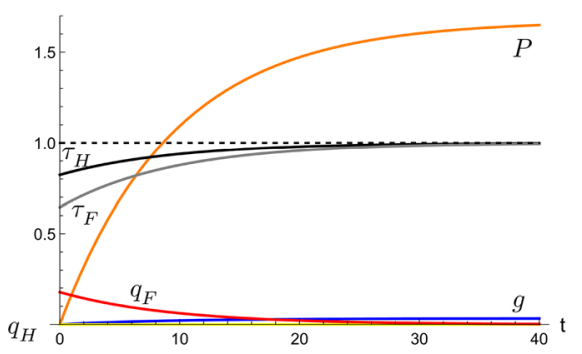

(b)

Fig. 4 Markov-perfect strategies in state space (a), optimal trajectories over time (b)

are possible. Intuitively, a subsidy is initially feasible only if $F$ is able to cope with both the damages from geoengineering and increased temperature, i.e. if in addition to (19) $\alpha_{\mathrm{F}}$ is sufficiently small,

$$
\alpha_{\mathrm{F}}<\check{\alpha}_{\mathrm{F}} \text {, with } \check{\alpha}_{\mathrm{F}}=2\left[r\left(1+\alpha_{\mathrm{H}}\right)-2 \alpha_{\mathrm{H}} \beta\right]\left[r\left(1+\alpha_{\mathrm{H}}\right)-\alpha_{\mathrm{H}} \beta\right] .
$$

Since $M<0$ and $N>0$, we find that the intercept of the optimal tariff for the home country is larger and that the slope is smaller compared to that for the foreign country. Our assumption of $\delta=0$ ensures that $\lim _{t \rightarrow \infty} \tau_{\mathrm{H}}=\lim _{t \rightarrow \infty} \tau_{\mathrm{F}}=1$, implying $\tau_{\mathrm{H}}>\tau_{\mathrm{F}}$ for all $t$. This, in turn, means that the quantity produced by $F$ 's firm is larger than that for $H$ 's. In fact, $F$ again designs its tax scheme in such a way that $H$ 's firm is deterred to export to $F$,

$$
q_{\mathrm{H}}=0, \quad q_{\mathrm{F}}=-M+\left(\frac{r}{2}-N\right) P,
$$

which means that the market is characterized by potential but not actual competition (similar but different to contestable markets a la Baumol [4]). In this sense geoengineering introduces a new damage term that country $F$ has to account for. This threat by $H$ forces $F$ to lower the production of its own industry over time. A typical set of optimal controls, the state and production quantities are depicted in Fig. 4, where we used $r=0.03, \alpha_{\mathrm{H}}=0.02, \alpha_{\mathrm{F}}=0.015$ and $\beta=0.3$.

Note that since $\alpha_{\mathrm{F}}>0$ an explosion in the state similar to the previous subsection is not optimal. $F$ needs to correct its production not only for the threat of geoengineering from $H$ but also for increased temperatures stemming from said production. We find

$$
P_{\infty}=\frac{M}{r / 2-N}
$$

\section{Conclusions}

First experiments of SRM are already underway. However, more research is needed not only on technical but also on economic aspects which may arise before, during and after implementing climate engineering techniques. This paper extends the economic literature by investigating bilateral trade relationships between a geoengineering country and its geoengineering-averse trade partner for different industrial organizations (monopoly, duopoly) and trade policies. We find that geoengineering may induce countries with no or negligible production to increase import tariffs (depending on the level of their aversion to geoengineering) and that it could induce producing nations to enforce a trade restriction even 
if they do not suffer or care about increasing temperature levels. This analysis highlights possible future international tensions due to geoengineering which can induce tariffs and thereby lead to a loss in global welfare. Of course, this tariff policy cannot serve as a mean to sufficiently mitigate global warming since the reduction in trade cannot be large enough in order to solve the problem. In fact, lowering trade by imposing tariffs gives geoengineering countries more 'room' for their domestic emissions, which we have not explicitly analysed in this paper due to the focus on trade. Our warning is that unilateral applications of geoengineering can lead to protectionist policies and in turn to international frictions among key players that render a global cooperative climate policy even harder to achieve or to maintain. While research on technical and meteorological consequences of climate engineering is critical, it is also necessary to study and to account for social preferences and attitudes before geoengineering is implemented in order to assess the scope of possible ramifications for each party. This means that a comprehensive discussion on the impacts of climate engineering should include potential effects on global trade flows as well as all other potential side effects. Of course, this framework is just among the first steps for further investigations. Extensions and alternatives are to include costly abatement, carbon capture and storage or other $\mathrm{CO}_{2}$ removal techniques (already built in most of the climate models run by the IPCC) and R\&D. Other potential extensions are in the directions of uncertainty (e.g. treating temperature increases as a stochastic process) or nonlinearities including the possibilities of tipping points and the threat of catastrophes.

Acknowledgements Open access funding provided by University of Vienna.

Open Access This article is distributed under the terms of the Creative Commons Attribution 4.0 International License (http://creativecommons.org/licenses/by/4.0/), which permits unrestricted use, distribution, and reproduction in any medium, provided you give appropriate credit to the original author(s) and the source, provide a link to the Creative Commons license, and indicate if changes were made.

\section{References}

1. Bala G, Duffy PB, Taylor KE (2008) Impact of geoengineering schemes on the global hydrological cycle. Proc Natl Acad Sci 105(22):7664-7669

2. Barrett S (2008) The incredible economics of geoengineering. Environ Resour Econ 39(1):45-54

3. Barrett S, Dannenberg A (2016) An experimental investigation into 'pledge and review' in climate negotiations. Clim Change 138(1):339-351

4. Baumol WJ, Panzar JC, Willig RD (1982) Contestable markets and the theory of industry structure. Harcourt Brace Jovanovich, San Diego

5. Bertoldi P (2011) Assessment and experience of white certificate schemes in the European union. European Commission, Directorate General JRC, New York

6. Buchanan JM (1969) External diseconomies, corrective taxes, and market structure. Am Econ Rev 59(1):174-177

7. Clark G (2008) A farewell to alms: a brief economic history of the world. Princeton University Press, Princeton

8. Corner A, Pidgeon N, Parkhill K (2012) Perceptions of geoengineering: public attitudes, stakeholder perspectives, and the challenge of ‘upstream' engagement. Wiley Interdiscip Rev Clim Change 3(5):451466

9. Dockner EJ, Long N (1993) International pollution control: cooperative versus noncooperative strategies. J Environ Econ Manag 25(1):13-29

10. Dockner EJ, Jorgensen S, Long N, Sorger G (2000) Differential games in economics and management science. Cambridge University Press, Cambridge

11. Heyen D, Wiertz T, Irvine PJ (2015) Regional disparities in SRM impacts: the challenge of diverging preferences. Clim Change 133(4):557-563 
12. Heyen D, Horton J, Moreno-Cruz JB (2017) Strategic implications of counter-geoengineering: escalation, cooperation, or nonuse? Working paper

13. Lenton TM, Held H, Kriegler E, Hall JW, Lucht W, Rahmstorf S, Schellnhuber HJ (2008) Tipping elements in the Earth's climate system. Proc Natl Acad Sci 105(6):1786-1793

14. Manoussi V, Xepapadeas A (2017) Cooperation and competition in climate change policies: mitigation and climate engineering when countries are asymmetric. Environ Resour Econ 66(4):605-627

15. Millard-Ball A (2012) The tuvalu syndrome. Clim Change 110(3):1047-1066

16. Moreno-Cruz JB, Keith DW (2013) Climate policy under uncertainty: a case for solar geoengineering. Clim Change 121(3):431-444

17. Nordhaus W (1991) To slow or not to slow: the economics of the greenhouse effect. Econ J 101:920-937

18. Nordhaus W (2007) A review of the stern review on the economics of climate change. JEcon Lit 45(3):686702

19. Nordhaus W (2015) Climate clubs: overcoming free-riding in international climate policy. Am Econ Rev 105(4):1339-1370

20. Robock A (2008) 20 Reasons why geoengineering may be a bad idea. Bull At Sci 64(2):14-18

21. Ruff L (1988) Least-cost-planning and demand-side-management: six common fallacies and one simple truth. Public Util Fortn 121:19-26

22. Schelling TC (1996) The economic diplomacy of geoengineering. Clim Change 33(3):303-307

23. Schmidt H, Alterskjær K, Bou Karam D, Boucher O, Jones A, Kristjánsson JE, Niemeier U, Schulz M, Aaheim A, Benduhn F, Lawrence M, Timmreck C (2012) Solar irradiance reduction to counteract radiative forcing from a quadrupling of $\mathrm{CO}_{2}$ : climate responses simulated by four earth system models. Earth Syst Dyn 3(1):63-78

24. The Royal Society (2009) Geoengineering the climate: science, governance and uncertainty. The Royal Society, London

25. Tsutsui S, Mino K (1990) Nonlinear strategies in dynamic duopolistic competition with sticky prices. J Econ Theory 52(1):136-161

26. Urpelainen J (2012) Geoengineering and global warming: a strategic perspective. Int Environ Agreem Polit Law Econ 12(4):375-389

27. Victor DG (2008) On the regulation of geoengineering. Oxf Rev Econ Policy 24(2):322-336

28. Weitzman ML (2015) A voting architecture for the governance of free-driver externalities, with application to geoengineering. Scand J Econ 117(4):1049-1068

29. Wirl F (2014) Taxes versus permits as incentive for the intertemporal supply of a clean technology by a monopoly. Resour Energy Econ 36(1):248-269 